\title{
Selectivity in Methanol Oxidation as Studied on Model Systems Involving Vanadium Oxides
}

\author{
Y. Romanyshyn $\cdot$ S. Guimond $\cdot$ H. Kuhlenbeck $\cdot$ S. Kaya $\cdot$ R. P. Blum $\cdot$ \\ H. Niehus - S. Shaikhutdinov • V. Simic-Milosevic · N. Nilius • \\ H.-J. Freund · M. V. Ganduglia-Pirovano - R. Fortrie · J. Döbler • \\ J. Sauer
}

Published online: 21 August 2008

(c) The Author(s) 2008. This article is published with open access at Springerlink.com

\begin{abstract}
Oxidation catalysts are modeled by oxide single crystals, thin oxide films, as well as supported oxide nanoparticles. We characterize the surface of those materials using a variety of surface sensitive techniques including scanning tunneling microscopy and spectroscopy, photoelectron spectroscopy, infrared spectroscopy, and thermal desorption spectroscopy. We find temperature dependent structural transformations from $\mathrm{V}_{2} \mathrm{O}_{5}(001)$ to $\mathrm{V}_{2} \mathrm{O}_{3}(0001)$ via $\mathrm{V}_{6} \mathrm{O}_{13}$ (001). $\mathrm{V}_{2} \mathrm{O}_{3}(0001)$ is found to be vanadyl terminated in an oxygen ambient and it loses the vanadyl termination after electron bombardment. It is shown that the concentration of vanadyl groups controls the selectivity of the methanol oxydehydrogenation towards formaldehyde. A proposal for the mechanism is made. The results on single crystalline thin films are compared with similar measurements on deposited vanadia nanoparticles. The experimental results are correlated with theoretical calculations and models.
\end{abstract}

Y. Romanyshyn · S. Guimond · H. Kuhlenbeck · S. Kaya · R. P. Blum · S. Shaikhutdinov · V. Simic-Milosevic . N. Nilius · H.-J. Freund $(\square)$

Abteilung Chemische Physik, Fritz-Haber-Institut der MaxPlanck-Gesellschaft, Faradayweg 4-6, Berlin 14195, Germany

e-mail: freund@fhi-berlin.mpg.de

R. P. Blum · H. Niehus

Institut für Physik, Humboldt-Universität zu Berlin,

Unter den Linden 6, Berlin 10099, Germany

M. V. Ganduglia-Pirovano · R. Fortrie · J. Döbler .

J. Sauer $(\bowtie)$

Institut für Chemie, Humboldt-Universität zu Berlin,

Unter den Linden 6, Berlin 10099, Germany

e-mail: js@chemie.hu-berlin.de
Keywords Oxide surfaces - Oxidation catalysis · Density functional calculations - Surface science . Catalysis $\cdot$ Methanol oxidation

\section{Introduction}

Vanadium oxides supported by a second oxide such as $\mathrm{TiO}_{2}$, $\mathrm{SiO}_{2}$, or $\mathrm{Al}_{2} \mathrm{O}_{3}$ represent an important class of active catalysts industrially applied to a variety of reactions. These include oxidation as well as reduction reactions, e.g., the oxidation of $o$-xylene to phthalic anhydride, the oxidation of sulfur dioxide to sulfur trioxide, the ammoxidation of aromatic hydrocarbons, and the selective catalytic reduction of $\mathrm{NO}_{x}$ with ammonia [1, 2]. Typically, submonolayer to monolayer quantities of vanadium oxides are dispersed on the substrate using impregnation, grafting, or chemical vapor deposition techniques followed by calcination cycles. Numerous investigations have been dedicated to the role of the support oxide and to the identification of active species. It was found that the choice of the support oxide can influence the activity of a catalyst system by several orders of magnitude $[1,2]$. The reducibility of the support oxide and the coupling between the support and vanadia, mediated via $\mathrm{V}-\mathrm{O}$ support bonds, have been proposed to play a decisive role [3-6]. However, many questions remain unanswered, such as the role of vanadyl groups or of vanadium oxides in an oxidation state lower than $+5[1,2]$.

Theoretical studies by density functional theory (DFT) for vanadium oxide species supported on silica revealed the key steps of the oxidation of methanol to formaldehyde [7]. First methanol binds on the surface by heterolytically splitting the $\mathrm{V}-\mathrm{O}-\mathrm{Si}$ interface bond (Scheme 1).

The second step is the redox step, a hydrogen atom is transferred from the methyl group to the vanadyl oxygen 


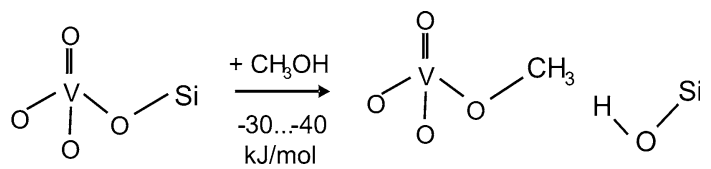

Scheme 1 Binding of methanol on isolated vanadia sites on silica

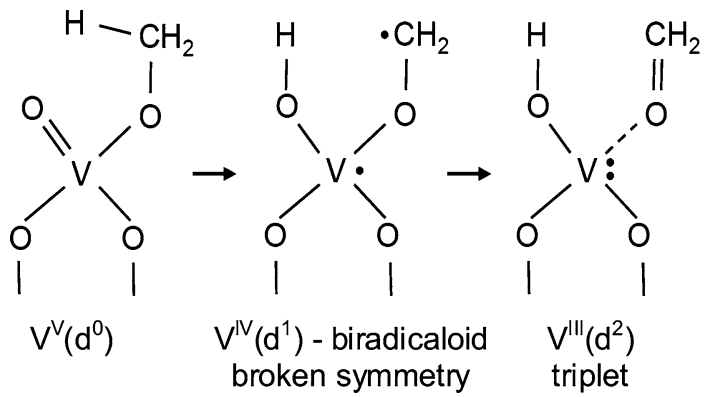

Scheme 2 Oxidation of surface bound methanol to formaldehyde

atom which creates a kind of biradical structure with an unpaired electron at the ${ }^{\circ} \mathrm{CH}_{2} \mathrm{O}$ - group and one electron in the vanadium $\mathrm{d}$-states. The reaction is completed when the $\mathrm{V}-\mathrm{O}\left(\mathrm{OCH}_{2}{ }^{\circ}\right)$ bond splits releasing formaldehyde and a second electron goes into the vanadium d-states (Scheme 2).

To obtain a more direct insight into structure-reactivity relations supported vanadia systems have been prepared under ultrahigh vacuum conditions on silica, alumina, and ceria thin film supports [8-16]. Scanning tunneling microscopy has been used to show that under such conditions the vanadia does not wet the surfaces of silica and alumina even if those surfaces had been exposed to water beforehand. Rather the vanadia particles grow three dimensionally. The vibrational and electronic properties of such model systems have been investigated with infrared spectroscopy and X-ray photoelectron spectroscopy and the analysis has been compared with the equivalent information from real catalysts [11]. It was found, in particular, that the vanadium oxidation state is +3 in the bulk but +5 at the surface where the vanadium is fourfold coordinated to three oxygen atoms in the surface plane and to one oxygen atom via a vanadium-oxygen double bond (vanadyl) perpendicular to the surface plane. It is expected that the vanadyl oxygen is a decisive factor for the surface chemistry.

The role of vanadyl species will be investigated in this paper with respect to alcohol oxidation even though in this case the process used commercially involves silver and ironmolybdate catalysts $[17,18]$. In this publication we present detailed catalytic studies on alcohol oxidation for supported vanadia and for ordered $\mathrm{V}_{2} \mathrm{O}_{3}(0001)$ thin films grown on $\mathrm{Au}(111)$. Similar to the case of the supported vanadia particles the ordered films exhibit vanadium in a +3 oxidation state in the bulk and +5 at the surface which is terminated by a layer of vanadyl groups $[19,20]$.
Also, we address the interconversion of vanadium oxides. Specifically, we will report changes of the surface structure of a $\mathrm{V}_{2} \mathrm{O}_{5}(001)$ single crystal surface upon heat treatment. The experimental studies are paralleled by theoretical investigations using electronic structure calculations and Monte Carlo simulations [21].

\section{Experimental}

The experiments have been performed in a number of different ultrahigh vacuum chambers. The setups are described in the literature. The $\mathrm{V}_{2} \mathrm{O}_{5}(001)$ single crystal surfaces were prepared by cleavage in UHV using adhesive tape [21].

The preparation of vanadia clusters on silica follows the recipes described in ref. [8-11] and the synthesis of the thin vanadia films has been detailed in Ref. $[16,19]$. The $\mathrm{V}_{2} \mathrm{O}_{3}$ films have been either used as prepared or they have been reduced by electron bombardment before exposure to the alcohol. Methanol has been dosed from a capillary doser typically at low temperature $(\sim 80 \mathrm{~K})$ before annealing to given temperature.

\section{Theoretical Calculations}

Calculations are based on spin-DFT and employ a planewave basis set as implemented in the Vienna $\mathrm{Ab}$ initio Simulation Package (VASP). We use gradient corrected exchange-correlation (GGA) functionals (PW91 or PBE) $[22,23]$. The electron-core interaction is described by the projector augmented wave (PAW) method [24]. The clean and defective $\mathrm{V}_{2} \mathrm{O}_{5}(001)$ surfaces are modeled using a fully relaxed two-layer slab and an energy cutoff of $800 \mathrm{eV}$. We have considered a wide range of defect concentrations $(1 / 6 \leq \Theta \leq 1)$. In order to rationalize the scanning tunneling spectra we also perform GGA + U calculations with $\mathrm{U}=3 \mathrm{eV}$ [25]. Furthermore, we employ the Monte Carlo method with pair interaction energies between reduced sites fitted to the DFT results to simulate the reduced $\mathrm{V}_{2} \mathrm{O}_{5}(001)$ surface at a given temperature and defect concentration. The network consists of 50 double rows of $2 \times 150$ sites, which corresponds to an area of $57.75 \times 53.7 \mathrm{~nm}^{2}$. Ten trajectories, starting from random states, are simulated using the Metropolis algorithm [26] for a varying fraction of reduced sites $(0-100 \%$, every $2.5 \%)$.

For the study of the oxidation of methanol to formaldehyde on $\mathrm{V}_{2} \mathrm{O}_{3}(0001)$ surfaces we employed a four-layer slab with a $(2 \times 2)$ periodicity and a $400 \mathrm{eV}$ cutoff; the $\left(\mathrm{V}-\mathrm{O}_{3}-\mathrm{V}\right)$ bottom layer is kept fixed at its position in the fully relaxed slab representing the clean surface. 
Fig. 1 (a) Scanning tunneling microscopy image of a $\mathrm{V}_{2} \mathrm{O}_{5}(001)$ single crystal surface revealing the double rows of vanadyl-oxygen atoms protruding out of the surface. (b) Schematic representation of Fig. 1a. (c) $\mathrm{V}_{2} \mathrm{O}_{3}$ resulting from $\mathrm{V}_{2} \mathrm{O}_{5}$ reduction. (d) Schematic view of oxygen and vanadium layer stacking in $\mathrm{V}_{2} \mathrm{O}_{3}(0001)$

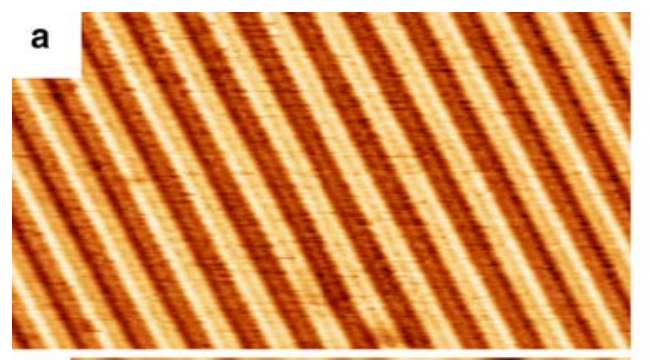

b
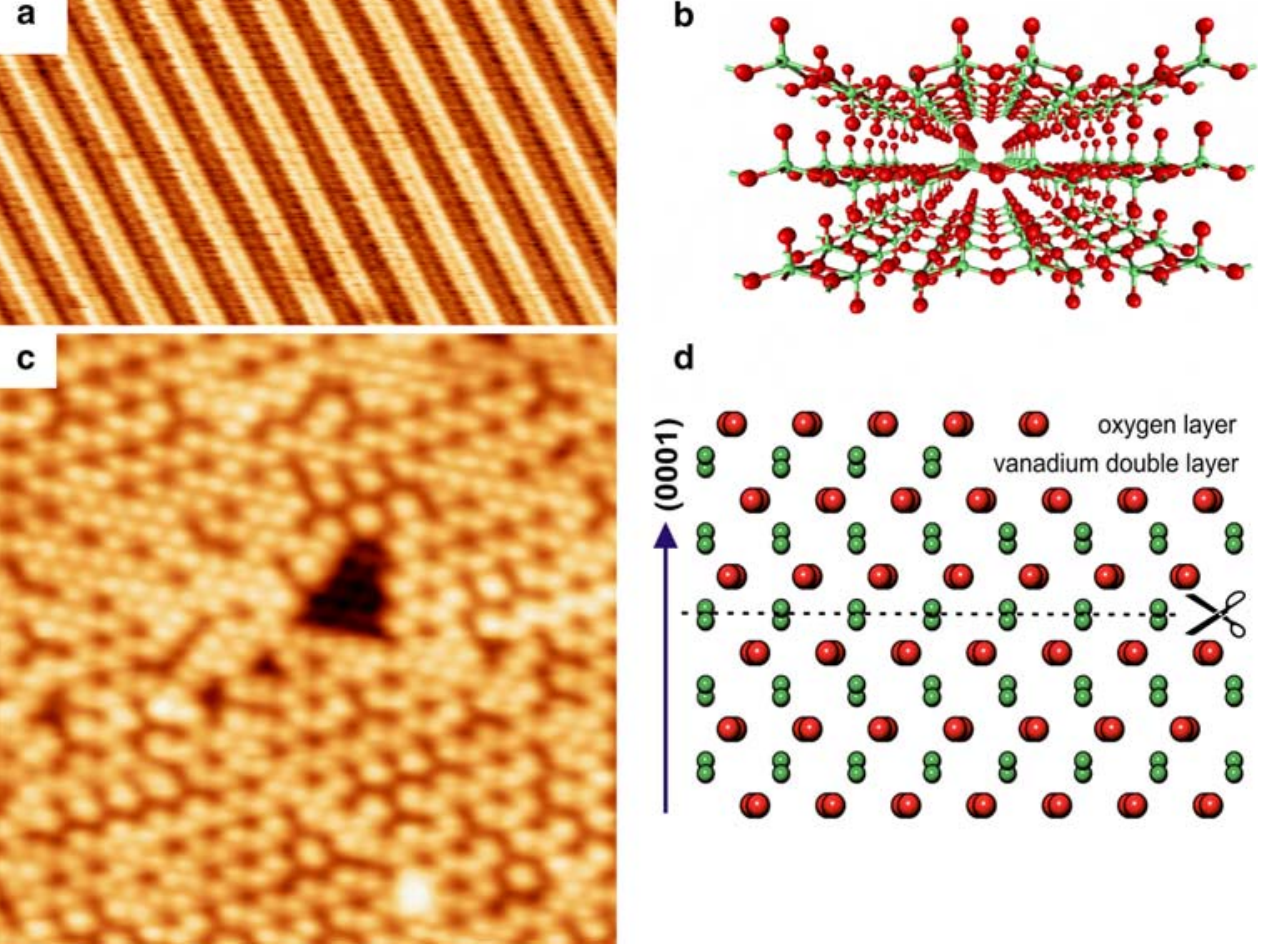

d

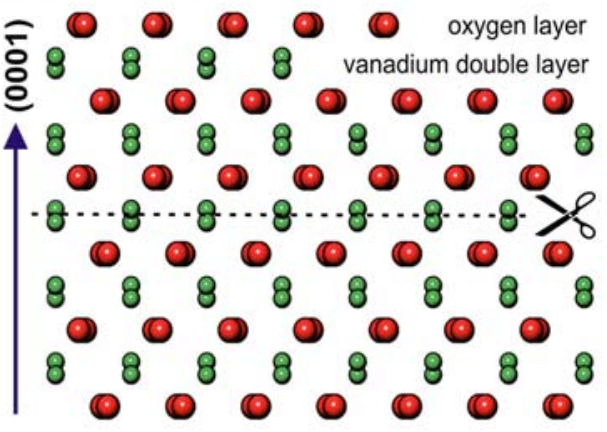

\section{Results and Discussion}

To analyze the surface properties of vanadia based catalysts we have studied single crystalline systems as in Ref. [21]. Figure 1a shows a scanning tunneling microscopy image of a $\mathrm{V}_{2} \mathrm{O}_{5}(001)$ single crystal surface revealing the double rows of vanadyl-oxygen atoms protruding out of the surface of the $\mathrm{V}_{2} \mathrm{O}_{5}(001)$ sheets which are held together by van der Waals forces along the (001) direction as expected from the bulk structure schematically represented in Fig. 1b. This surface undergoes a transformation via $\mathrm{V}_{6} \mathrm{O}_{13}$ towards $\mathrm{V}_{2} \mathrm{O}_{3}(0001)$ keeping its single crystallinity over large areas of the macroscopic surface. The final result of a $\mathrm{V}_{2} \mathrm{O}_{3}(0001)$ surface shows in Fig. 1c the typical hexagonal lattice of protrusions of a depolarized corundum type (0001) surface, which is expected to be terminated by half a metal ion layer with exactly the exposed surface unit cell, if the surface structure is directly derived from a cut through the bulk structure in between the puckered vanadium ion layers [16]. This situation is depicted in Fig. 1d. It will become clear further below in this paper that the surface is, in fact, not terminated in this way but rather by a layer of $\mathrm{V}=\mathrm{O}$ (vanadyl) bonds with the same registry [16].

Before we discuss the evidence for this we present details for the first steps of the processes involved in the transformation from $\mathrm{V}_{2} \mathrm{O}_{5}(001)$ towards $\mathrm{V}_{6} \mathrm{O}_{13}$ and $\mathrm{V}_{2} \mathrm{O}_{3}$ respectively. Figure $2 \mathrm{a}$ and $\mathrm{b}$ shows color coded gap maps of a $\mathrm{V}_{2} \mathrm{O}_{5}$ surface after heating to 350 and $400 \mathrm{~K}$, respectively. To construct these maps we measured scanning tunneling spectra for every pixel, i.e. the derivative of the I-V-curve as a function of the tip voltage. The blue, red and yellow areas correspond to regions of different gap width. The corresponding scanning tunneling spectra are revealed in Fig. 2c. The blue trace has been taken on a fully oxidized $\mathrm{V}_{2} \mathrm{O}_{5}(001)$ surface at $300 \mathrm{~K}$ exhibiting a $1.8 \mathrm{eV}$ gap and well ordered structure, while the yellow and red pixels stem from disordered and already reduced parts in which we observe a smaller gap (yellow) and a closed gap (red). Those changes have been modeled using DFT $+\mathrm{U}$ and Monte Carlo simulations. The DFT $+\mathrm{U}$ calculated density of states (DOS) of the clean $\mathrm{V}_{2} \mathrm{O}_{5}(001)$ surface yields a band gap of $\sim 2.3 \mathrm{eV}$ (Fig. 2f), which is similar to the measured value $(\sim 1.8 \mathrm{eV})$. The formation of isolated vanadyl oxygen defects results in the reduction of the band gap down to $\sim 1.1 \mathrm{eV}$, whereas the formation of defect pairs along the [010] direction leads to a band gap of $\sim 0.5 \mathrm{eV}$, and a trench-like structure with missing rows of vanadyl-oxygen atoms exhibits a metallic character. Earlier plain DFT-PW91 calculations of reduced $\mathrm{V}_{2} \mathrm{O}_{5}(001)$ surfaces predicted the facile reduction along the direction of the vanadyl rows [27]. Therefore, we ascribe the red and yellow areas in Fig. $2 \mathrm{a}$ and $\mathrm{b}$ to randomly distributed isolated vanadyl oxygen defects and to the missing-row phase, respectively. Monte Carlo simulations at $300 \mathrm{~K}$ and UHV conditions $\left(10^{-10}\right.$ mbar of $\left.\mathrm{O}_{2}\right)$ for $3 \%$ (Fig. 2d) and 7\% (Fig. 2e) of reduced sites combined with the DFT + U band gaps result in simulated band gap maps which exhibit a disordered pattern with the same amount of 
Fig. 2 (a, b) Band gap maps of the $\mathrm{V}_{2} \mathrm{O}_{5}(001)$ surface recorded at $350 \mathrm{~K}$ (a) and $400 \mathrm{~K}(\mathbf{b}) .(\mathbf{c})$ Normalized conductance spectra over areas A and B at $350 \mathrm{~K}$, and over $\mathrm{V}_{2} \mathrm{O}_{5}(001)$ at 300 K. (d, e) Simulated gap maps at $300 \mathrm{~K}$ for $3 \%$ (d) and $7 \%$ (e) of reduced sites. The local band gap value was taken equal to the smallest gap within a radius of $2.78 \mathrm{~nm}$. The band gap scale (in eV) is indicated. (f) Calculated density of states of the clean $\mathrm{V}_{2} \mathrm{O}_{5}(001)$ surface (blue), of the defective surface containing isolated vanadyloxygen vacancies (yellow), and of the missing-row structure (red). The curves are smoothed by a Gaussian level broadening of $0.2 \mathrm{eV}$
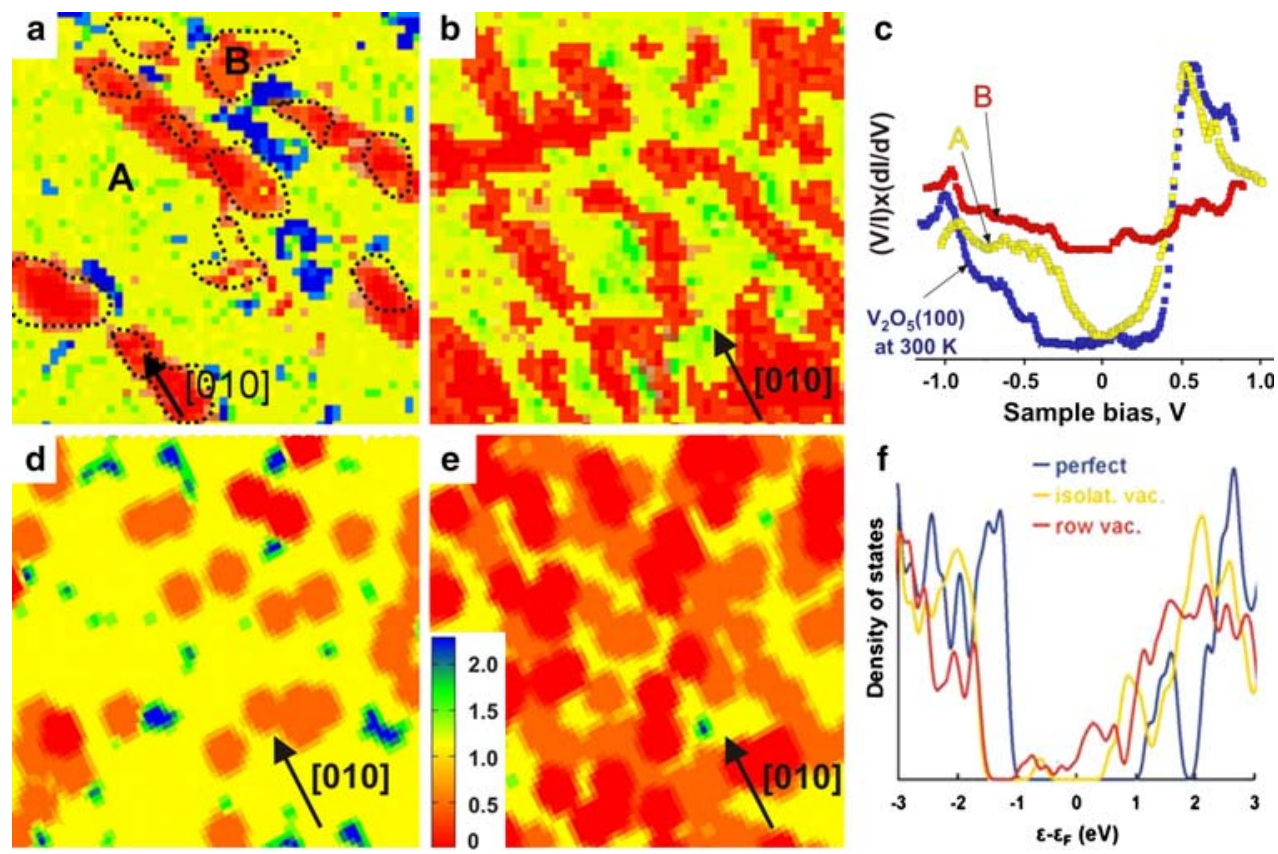

red and yellow areas as the experimental ones. Hence, the anisotropic growth of vanadyl oxygen vacancies is concomitant with an insulator-to-metal transition at the surface.

We now return to the $\mathrm{V}_{2} \mathrm{O}_{3}(0001)$ surface as imaged in Fig. 1c. We have shown earlier that this surface is terminated by a layer of vanadyl groups, increasing the formal oxidation state from $\mathrm{V}^{3+}$ in the bulk to $\mathrm{V}^{5+}$ at the surface $[14,15]$. Synchrotron based photoemission studies were employed to prove this. Such a surface is completely unreactive with respect to methanol. Only physisorbed species have been observed and characterized by TDS and spectroscopic techniques. However, if the surface is reduced the situation changes considerably. We note that, different from $\mathrm{Cr}_{2} \mathrm{O}_{3}(0001)$ [28], where we encountered a similar structural situation, the vanadyl groups cannot be reduced thermally without destroying the surface structure $[16,19]$. In fact, it is necessary to electron bombard the surface to selectively remove the vanadyl oxygen atoms as shown in Fig. 3 and discussed in a previous paper [16]. Ultimately, all vanadyl oxygen atoms may be removed by this procedure and we are left with vanadium terminated surfaces just as it was indicated in Fig. 1d. This surface is very reactive with respect to a variety of different molecules, including $\mathrm{CO}, \mathrm{CO}_{2}, \mathrm{H}_{2} \mathrm{O}$ and alcohols [29]. There is no specific selectivity observed under those circumstances.
Fig. 3 STM images illustrating the reduction of vanadyl terminated $\mathrm{V}_{2} \mathrm{O}_{3}(0001)$ towards vanadium terminated $\mathrm{V}_{2} \mathrm{O}_{3}(0001)$ via electron irradiation $(500 \mathrm{eV})$. Images of the vanadyl terminated surface, the vanadium terminated surface (after irradiation with an electron dose of $80 \mathrm{mC}$ ), and two intermediated reduction states (electron doses of 1 and $10 \mathrm{mC}$ ) are shown
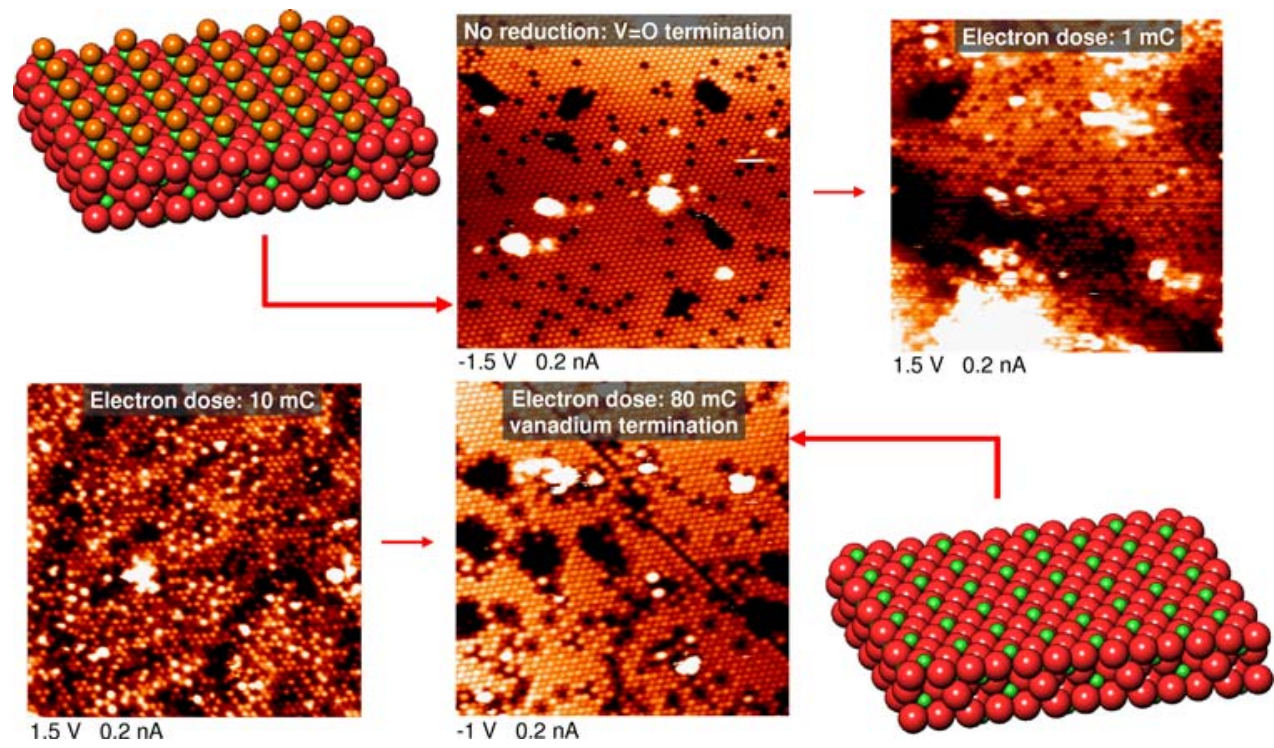

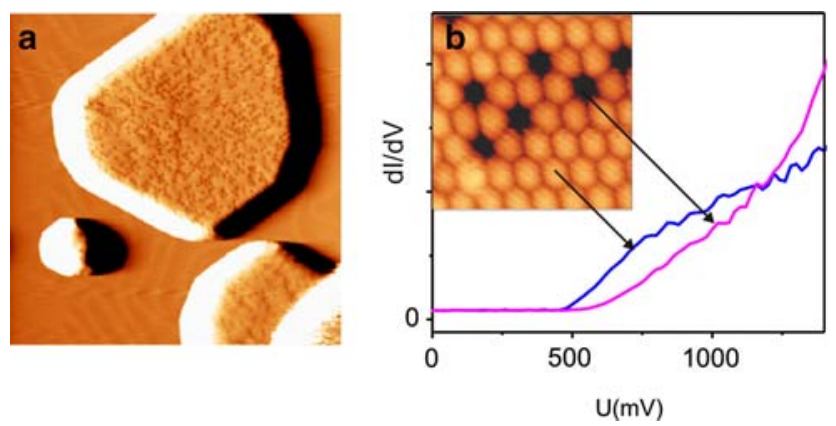

Fig. 4 (a) STM image of $\mathrm{V}_{2} \mathrm{O}_{3} / \mathrm{Au}(111)$ taken at $5 \mathrm{~K}(4.0 \times 4.0 \mathrm{~nm}$, $1.4 \mathrm{~V}, 100 \mathrm{pA}$ ). (b) dI/dV spectra taken at a defect site (violet line) and above a $\mathrm{V}=\mathrm{O}$ group (blue line). The additional $\mathrm{dI} / \mathrm{dV}$ intensity above the $\mathrm{V}=\mathrm{O}$ lattice is attributed to a $\mathrm{V}=\mathrm{O}$ related electronic state

The situation changes when we consider intermediate vanadyl coverages, i.e. situations where vanadyl groups as well as surface vanadium ion sites are exposed simultaneously. The results presented in the following have been obtained on thin $\mathrm{V}_{2} \mathrm{O}_{3}$ films grown on $\mathrm{Au}(111)$. Figure $4 \mathrm{a}$ shows an area at $5 \mathrm{~K}$ where a few vanadyl oxygen atoms have been removed (dark spots) [30]. Figure $4 \mathrm{~b}$ shows scanning tunneling spectra taken within an area where full vanadyl coverage is observed as opposed to a position where apparently an individual vanadyl oxygen atom is missing. Obviously, this very small variation in vanadyl oxygen coverage leads to a change in the local electronic structure, i.e. the surface band gap starts to close! Note that the band gap referred to here is the band gap in the surface region which may be different from the bulk band gap.

There are indications that even defects within the material influence the band gap at the surface, and that this band gap varies across the surface [30]. The band gap is believed to be important in oxidation reactions where redox processes involve electron transfer and intermediate storage [4]. It is therefore a working hypothesis to assume that a combination of the ensemble and the local band gap governs the reactivity [4-6].

In Fig. 5a we plot the reactivity of a $\mathrm{V}_{2} \mathrm{O}_{3}(0001)$ surface at two different degrees of reduction with respect to the formation of various reaction products as measured via TDS after exposing the surface to methanol at $\sim 90 \mathrm{~K}$. The black and the red traces correspond to mass 31 (methanol) and mass 29 (formaldehyde plus a methanol fragment which results from cracking in the mass-spectrometer), respectively. In addition we show water (mass 18), hydrogen (mass 2) and methane (mass 16). Below $200 \mathrm{~K}$ the desorption signals are basically determined by
Temperature [K]

100150200250300350400450500550600650700

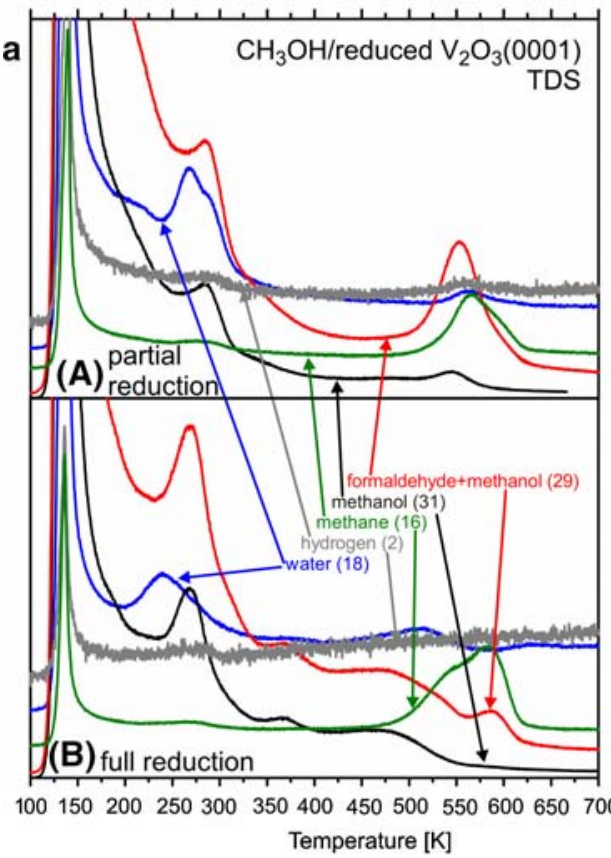

Fig. 5 (a) Thermal desorption spectra of a methanol multilayer on a partially reduced $\mathrm{V}_{2} \mathrm{O}_{3}(0001)$ surface (top, electron dose: $2 \mathrm{mC}$ ), and a fully reduced surface (bottom, electron dose: $80 \mathrm{mC}$, electron energy: $500 \mathrm{eV}$ ). Spectra for mass 2 (molecular hydrogen), 16 (methane), 18 (water), 29 (formaldehyde + methanol), and 31 (methanol) are shown. Methanol was adsorbed at 95 K. (b) Thermal desorption spectra of a methanol multilayer on $\mathrm{V}_{2} \mathrm{O}_{3}(0001)$ recorded

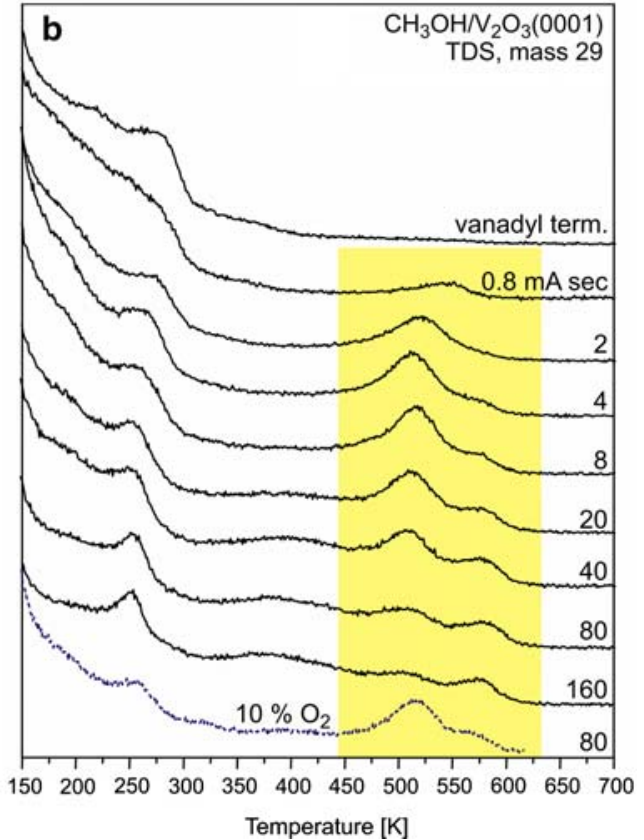

at mass 29 (methanol + formaldehyde) as a function of the degree of surface reduction. The originally vanadyl terminated $\mathrm{V}_{2} \mathrm{O}_{3}(0001)$ surface was reduced with different doses of electron irradiation $(500 \mathrm{eV})$ as given in the figure. At the bottom a spectrum of a methanol $(90 \%)$ plus oxygen $(10 \%)$ gas mixture is shown. The adsorbates were dosed at $90 \mathrm{~K}$ 
desorption of the methanol multilayer. A prominent peak at $\sim 275 \mathrm{~K}$ is assigned to the desorption of the methanol monolayer [29], essentially up to $500 \mathrm{~K}$ the desorption traces of $29 \mathrm{amu}$ (formaldehyde) and $18 \mathrm{amu}$ (water) follow the methanol signal (31 amu). The water signal at $\sim 250 \mathrm{~K}$ which does not follow methanol desorption is probably to be assigned to the reaction of hydroxyl groups resulting from the fission of methanol into methoxy and hydrogen [29]. An interesting point to note is the dependence of the selectivity for formaldehyde formation on the presence of vanadyl groups on the surface: their presence leads to an increased amount of produced formaldehyde and decreases the amount of formed methane indicating that the surface vanadyl groups are an important ingredient for the control of the selectivity of the $\mathrm{V}_{2} \mathrm{O}_{3}(0001)$ surface.

Above $500 \mathrm{~K}$ small traces of $\mathrm{H}_{2} \mathrm{O}$ are observed and a considerable signal at mass 29 which largely stems from formed formaldehyde as judged by the small intensity of the signal at mass 31 . After the onset of the formaldehyde signal we see desorption of methane as well as traces of $\mathrm{H}_{2} \mathrm{O}$ and hydrogen. All of the signals above $500 \mathrm{~K}$ are absent for a fully vanadyl covered surface (not shown here).

Figure $5 \mathrm{~b}$ shows a series of traces for mass 29 as a function of the degree of reduction of the $\mathrm{V}_{2} \mathrm{O}_{3}(0001)$ surface. There is a clear maximum of formaldehyde production at a moderate state of reduction corresponding to a $4 \mathrm{mC}$ dose of electrons reducing the surface (full reduction needs about $80 \mathrm{mC}$ ). Figure 6a shows STM images of this intermediate reduction stage before and after exposure to methanol and heating to $400 \mathrm{~K}$. The XPS data in Fig. $6 \mathrm{~b}$ as well as infrared data (Fig. 7 to be discussed below) indicate the presence of methoxy groups on this surface. Figure $6 \mathrm{~b}$ contains the C1s XPS data for methanol dosed at $100 \mathrm{~K}$ and consecutively heated to three different temperatures. The lowest trace is for methanol exposure at $100 \mathrm{~K}$ revealing spectra characteristic of methanol. At $550 \mathrm{~K}$ the states characteristic of methanol have entirely disappeared and a species with a C1s binding energy of $286.5 \mathrm{eV}$ remains. Indeed, the XPS binding energy of $286.5 \mathrm{eV}$ is typical for methoxy. Figure 7 shows temperature dependent IR spectra after exposure of the partially reduced surface (second trace from bottom) to methanol at $88 \mathrm{~K}$ and subsequent stepwise heating to $660 \mathrm{~K}$. In comparison, the spectrum of the fully vanadyl terminated surface is shown. The vanadyl groups had been partially labeled with ${ }^{18} \mathrm{O}$ isotopes giving rise to the doublet at 998 and $1032 \mathrm{~cm}^{-1}$ respectively. It is interesting to note that this doublet shifts by more than $10 \mathrm{~cm}^{-1}$ to lower energies (982 and $1021 \mathrm{~cm}^{-1}$, see the right panel) upon reduction indicating the influence of the modified electronic structure discussed above in connection with the low temperature

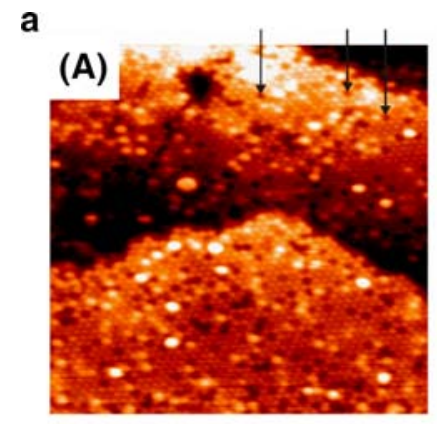

$1.5 \mathrm{~V}, 0.2 \mathrm{nA}, 20 \times 20 \mathrm{~nm}^{2}$

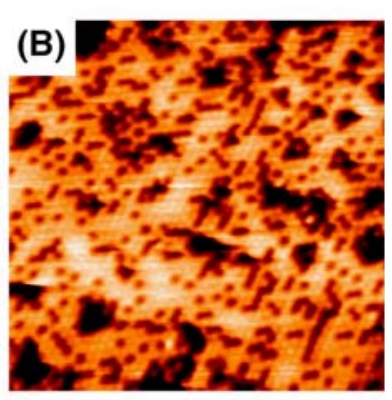

$-1.5 \mathrm{~V}, 0.2 \mathrm{nA}, 20 \times 20 \mathrm{~nm}^{2}$ b

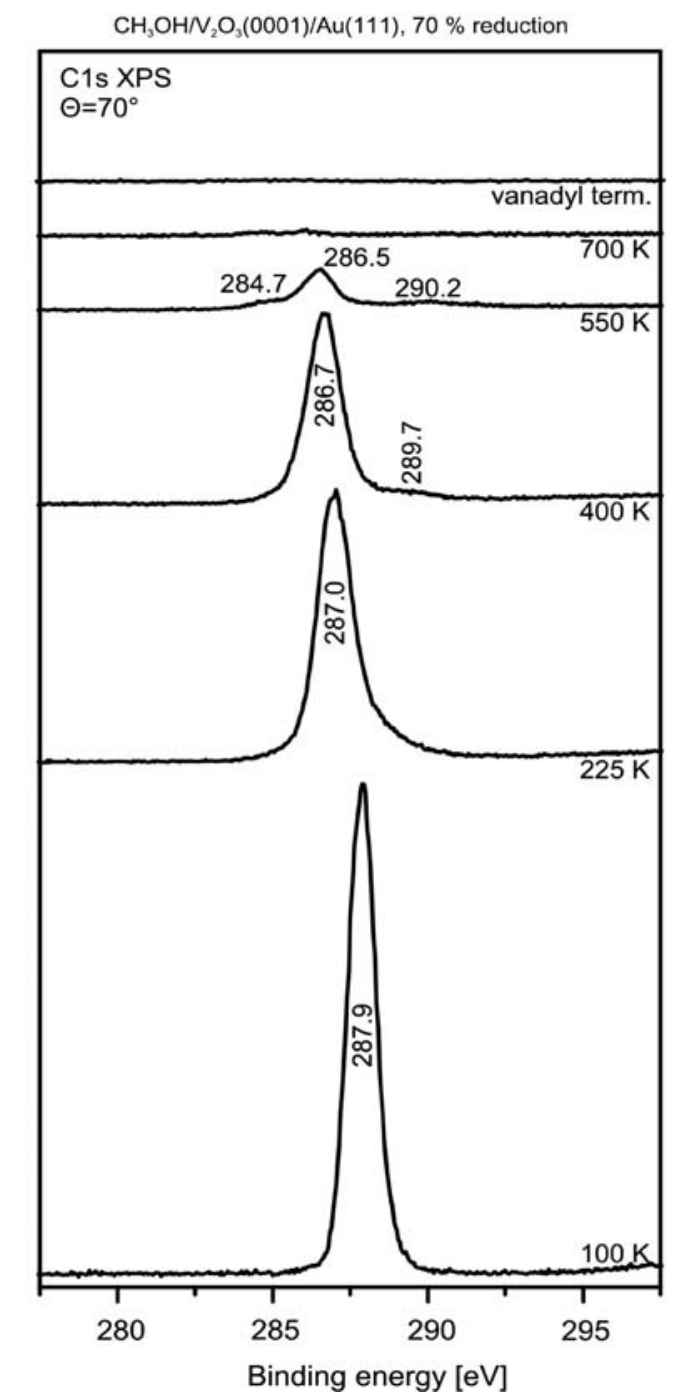

Fig. 6 (a) STM image of a weakly reduced surface (electron dose: $2 \mathrm{mC}$, electron energy: $500 \mathrm{eV}$ ). (b) STM image of the weakly reduced surface after exposure to methanol in multilayer amounts at $95 \mathrm{~K}$ and annealing at $400 \mathrm{~K}$. (b) $\mathrm{C} 1 \mathrm{~s}$-XPS spectra of reduced $\mathrm{V}_{2} \mathrm{O}_{3}(0001)$ after annealing at $400 \mathrm{~K}$. Methanol (three different doses: $0.2,0.75,2.25 \mathrm{~L}$ ) was dosed at $100 \mathrm{~K}$. The spectra were recorded with $\mathrm{Al} \mathrm{K} \alpha$ radiation at an electron exit angle of $70^{\circ}$ with respect to the surface normal 
Fig. 7 Infrared spectra of methanol adsorbed on fully reduced [panel (a), electron dose: $80 \mathrm{mC}$ ] and partially reduced [panel $(\mathbf{b})$, electron dose: $8 \mathrm{mC}] \mathrm{V}_{2} \mathrm{O}_{3}(0001)$ as a function of temperature. Methanol was adsorbed at $88 \mathrm{~K}$. Before recording a spectrum, the samples were shortly flashed to the temperature given at the respective spectrum and the spectra were recorded after the sample had cooled down to below $100 \mathrm{~K}$. The $\mathrm{V}_{2} \mathrm{O}_{3}(0001)$ substrate contains a mixture of ${ }^{18} \mathrm{O}$ and ${ }^{16} \mathrm{O}$. All spectra are referenced to the spectra of the respective reduced surfaces except the spectrum of the partially reduced and the vanadyl terminated surfaces in panel (b) which were referenced to the spectrum of the fully reduced surface of panel (a)
$\mathrm{CH}_{3} \mathrm{OH} /$ reduced $\mathrm{V}_{2} \mathrm{O}_{3}(0001)$
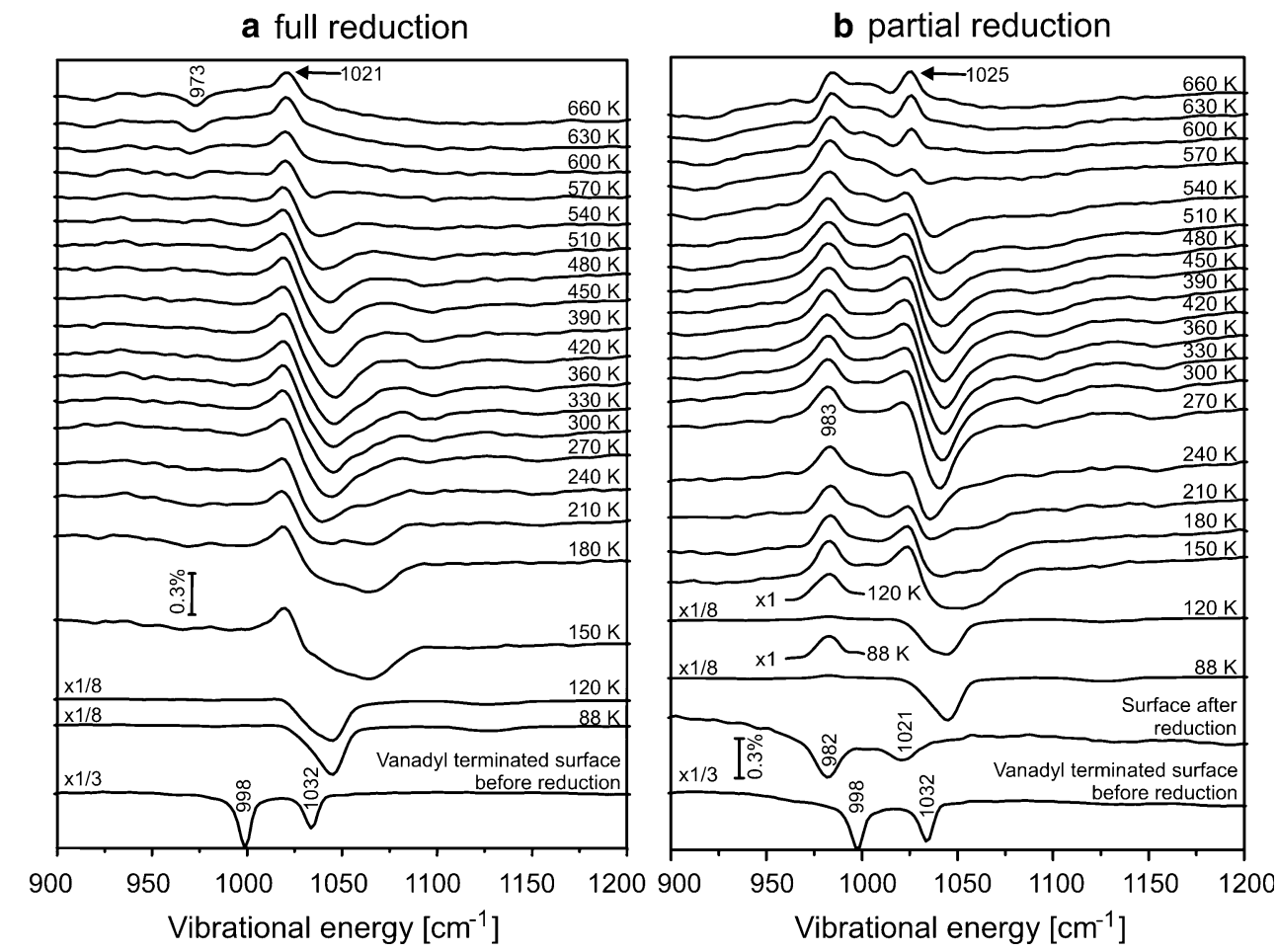

STM data. Upon exposure to methanol even at the lowest temperature the vanadyl vibrations disappear and methoxy bands appear in the spectra. This indicates that methanol first loses the hydrogen atom from the hydroxyl group and a $\mathrm{V}-\mathrm{OH}$ species must be formed.

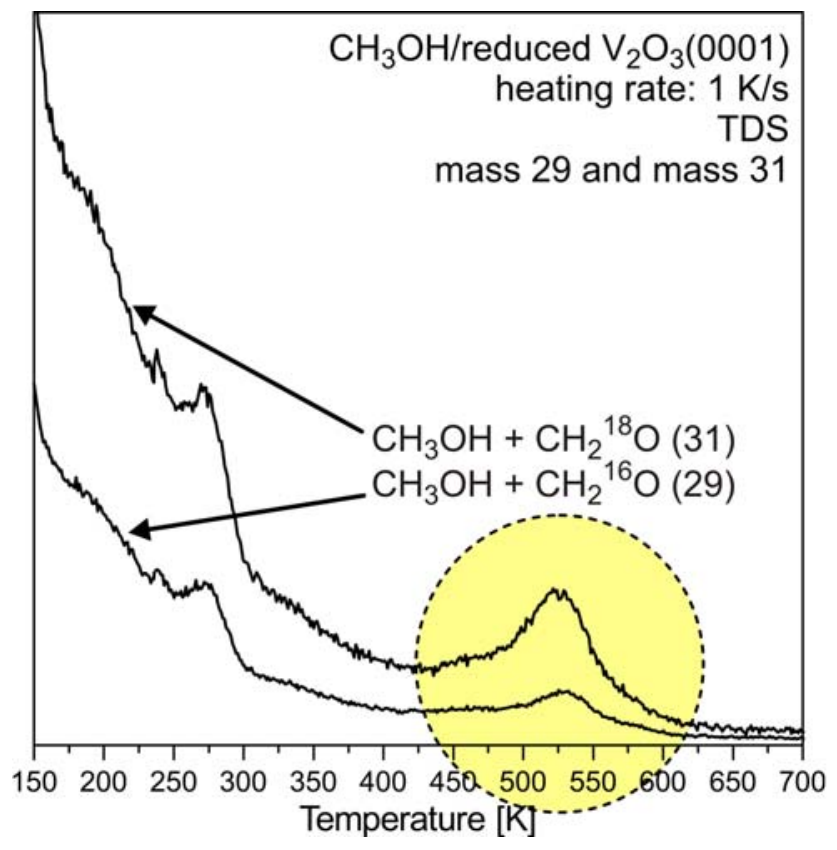

Fig. 8 Thermal desorption spectra (mass 29 and 31) of methanol on a weakly reduced $\mathrm{V}_{2} \mathrm{O}_{3}(0001)$ layer (electron dose: $8 \mathrm{mC}$ ) containing a mixture of ${ }^{16} \mathrm{O}$ and ${ }^{18} \mathrm{O}$. Methanol was adsorbed at $88 \mathrm{~K}$
The vanadyl groups are actively involved in the formaldehyde production as the formaldehyde produced contains both ${ }^{16} \mathrm{O}$ and ${ }^{18} \mathrm{O}$ if $\mathrm{CH}_{3}{ }^{16} \mathrm{OH}$ is dosed onto the surface that contains vanadyl groups formed from both isotopes as shown in Fig. 8.

It is clear that the mechanism involves both vanadyl and open vanadium surface ion sites, as schematically depicted in Scheme 3, see also Fig. 9. Methanol binds to the vanadium ion sites transferring the hydroxyl hydrogen to a vanadyl group with low activation energy. The methyl hydrogen is then transferred to another vanadyl group or directly to a $\mathrm{V}-\mathrm{OH}$ group leading to the formation of water. Alternatively, the methyl group could take up a hydrogen atom to form methane.

It is the hydrogen attachment to the vanadyl group that goes hand in hand with a change in the electron count and could be influenced by the ability of the vanadium oxide to accept and release electrons, which in turn is controlled by the vanadium oxide surface band gap.

The mechanism suggested by Scheme 3 is supported by DFT calculations using the PBE functional. The energy for molecular adsorption of methanol on the fully oxidized $\mathrm{V}_{2} \mathrm{O}_{3}(0001)$ surface is only $-16 \mathrm{~kJ} / \mathrm{mol}$. This step differs substantially from adsorption on silica supported vanadia shown in Scheme 1, for $\mathrm{V}_{2} \mathrm{O}_{3}$ forms a closely packed lattice and insertion of a methoxy group in a $\mathrm{V}-\mathrm{O}$ bond is not possible. On the reduced surface with a vanadyl defect concentration of $1 / 4$ we find stronger adsorption with energies of -122 and $-193 \mathrm{~kJ} / \mathrm{mol}$ for non-dissociative 
Scheme 3 Tentative reaction scheme for formaldehyde formation from methanol on $\mathrm{V}_{2} \mathrm{O}_{3}(0001)$ surfaces

$$
\begin{aligned}
\text { adsorption: } & \mathrm{CH}_{3} \mathrm{OH}+\mathrm{V}_{\text {(surf) }}+\mathrm{O}_{\text {(surf) }} \rightarrow \mathrm{CH}_{3} \mathrm{OV}_{\text {(surf) }}+\mathrm{HO}_{\text {(surf) }} \\
>470 \mathrm{~K}: & \mathrm{CH}_{3} \mathrm{OV}_{\text {(surf) }}+\mathrm{O}_{\text {(surf) }} \rightarrow \mathrm{CH}_{2} \mathrm{O} \uparrow+\mathrm{HO}_{\text {(surf) }}+\mathrm{V}_{\text {(surf) }} \\
& \mathrm{CH}_{3} \mathrm{OV}_{\text {(surf) }}+\mathrm{HO}_{\text {(surf) }} \rightarrow \mathrm{CH}_{4} \uparrow+2 \mathrm{O}_{\text {(surf) }}+\mathrm{V}_{\text {(surf) }} \\
& 2 \mathrm{HO}_{\text {(surf) }} \rightarrow \mathrm{H}_{2} \mathrm{O} \uparrow+\mathrm{O}_{\text {(surf) }}
\end{aligned}
$$

Fig. 9 Calculated structures of (a) molecular adsorption of methanol on $\mathrm{V}_{2} \mathrm{O}_{3}(0001)$, (b) dissociative adsorption, and (c) surface after methanol oxidation
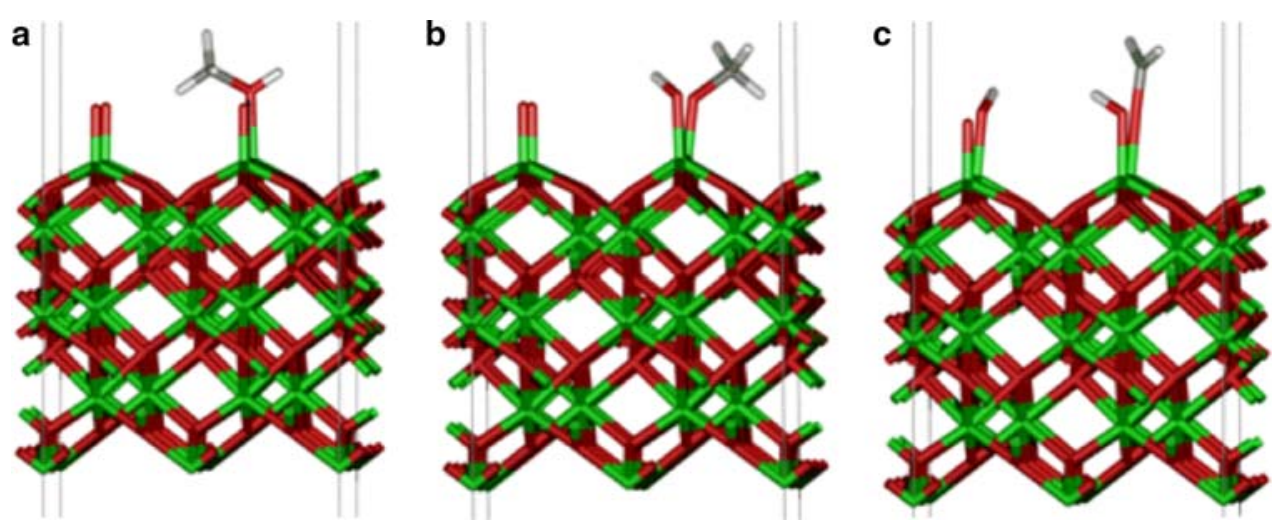

(Fig. 9a) and dissociative adsorption (Fig. 9b). The latter involves hydrogen transfer to a neighboring vanadyl group. Hydrogen transfer to a three-fold coordinated surface oxygen atom is much less favorable and results in an adsorption energy of only $-103 \mathrm{~kJ} / \mathrm{mol}$. The large energy difference underlines the importance of having both reduced and oxidized surface ion sites for dissociative methanol adsorption creating a hydroxyl and a methoxy site, respectively. In a second step, the methoxy group formed is oxidized to formaldehyde by hydrogen transfer to a neighboring vanadyl group (Fig. 9c). This redox step is similar to silica supported vanadia (Scheme 2). For this reaction we find a reaction energy of $+141 \mathrm{~kJ} / \mathrm{mol}$ with respect to the dissociative adsorption state. This reaction is only possible if two adjacent vanadyl sites are available on the surface, one for the initial adsorption and a second one for the oxidation step. For higher defect concentrations (1/ 2 ), dissociative adsorption is $20-30 \mathrm{~kJ} / \mathrm{mol}$ less exothermic. However, the main difference is that after adsorption vanadyl groups are no longer available. Hence, in the redox step, hydrogen has to be transferred to a three-fold coordinated surface oxygen atom, which is far more endothermic $(244 \mathrm{~kJ} / \mathrm{mol}$ with respect to the dissociative adsorption state). Hence, the effect of the defect concentration on these reactions energies is sizable. This result is supported by the TDS data presented in Fig. 5b which show a formaldehyde desorption peak at $550 \mathrm{~K}$ which grows at the expense of the state at $\sim 515 \mathrm{~K}$ when the degree of surface reduction is increased. In the light of the results of the calculation presented above, the peak at $515 \mathrm{~K}$ could be attributed to formaldehyde formed using vanadyl oxygen while the peak at higher temperature might be assigned to formaldehyde formed involving three-fold coordinated surface oxygen atoms.

So far we have discussed the reactivity of a well ordered surface. Realistically the reactions happen on systems where the vanadium oxide is supported on another oxide. We have studied in the past vanadium oxide $\left(\mathrm{VO}_{x}\right)$ deposits on alumina and on silica in order to clarify spectroscopic assignments previously proposed for powder samples using

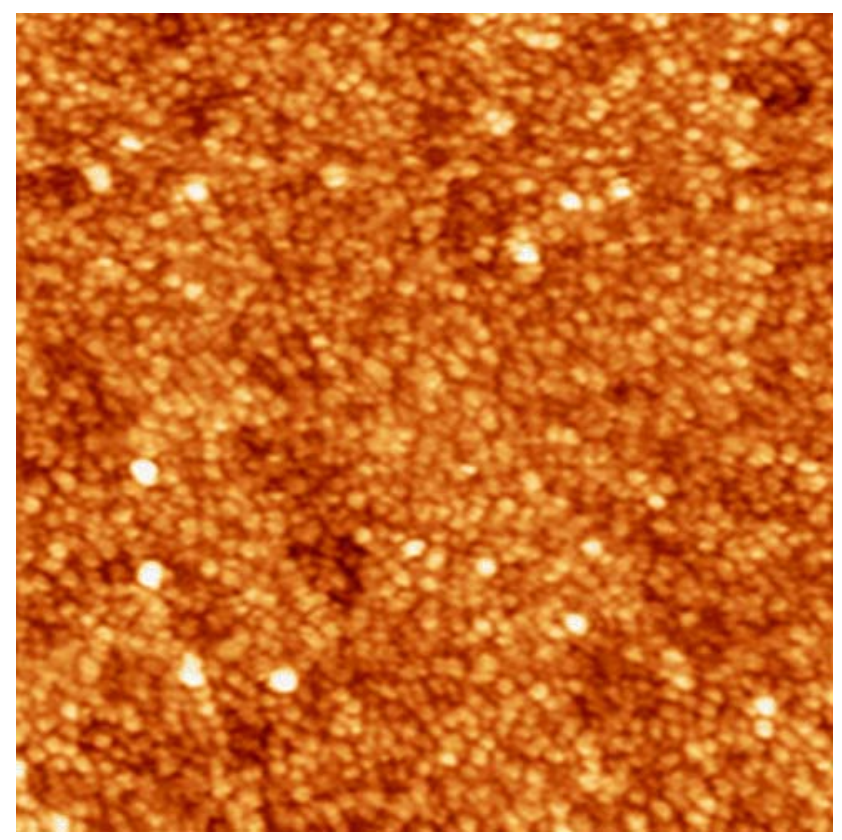

Fig. 10 Typical STM image of vanadia prepared by physical vapor deposition of vanadium in an oxygen ambient on silica and alumina films. Size: $100 \times 100 \mathrm{~nm}^{2}$ 
Raman spectroscopy [11]. The typical sample shows an STM image as shown in Fig. 10 where the vanadia is prepared by physical vapor deposition of vanadium in an oxygen ambient onto the surface of a silica film. The morphology of the film is granular indicating threedimensional growth of the vanadium oxide particles, which have been proven to be mainly $\mathrm{V}_{2} \mathrm{O}_{3}$ particles exposing vanadyl groups at their surface [8-11]. In this sense they are similar to the single crystal $\mathrm{V}_{2} \mathrm{O}_{3}(0001)$ surface. The morphology of the vanadium oxide deposits can only be modified within a very narrow range. Attempts have been made to deposit the vanadium within an oxygen ambient into a pre-deposited water (ice) layer [31] on the thin silica film surface. While this procedure does not lead to hydroxylation of the silica, the vanadium oxide particles expose $\mathrm{OH}$ and partially $\mathrm{V}=\mathrm{O}$ groups at $300 \mathrm{~K}$. Upon heating to $500 \mathrm{~K}, \mathrm{~V}_{2} \mathrm{O}_{3}$ particles are formed which mainly expose $\mathrm{V}$ sites [12]. Note that water assisted preparation slightly smoothes the vanadium oxide layer. When oxidized at $500 \mathrm{~K}$ in $10^{-6} \mathrm{mbar}$ of $\mathrm{O}_{2}$, the vibrational properties are very similar to that of the fully oxidized $\mathrm{V}_{2} \mathrm{O}_{3}(0001)$ surface. If such a system, fully vanadyl covered, is exposed to methanol, it is as unreactive as a fully $\mathrm{V}=\mathrm{O}$ covered $\mathrm{V}_{2} \mathrm{O}_{3}(0001)$ surface. For fully reduced vanadia particles (i.e. before oxidation treatment) we find some amount of formaldehyde in the desorption spectra. However, if the reduced particles prepared using water assisted preparation are exposed to oxygen at $300 \mathrm{~K}$ which leads to the partially reduced (or partially oxidized) surface (note that quantifying the state of reduction is even more difficult here than in the case of single crystal surface), the amount of formaldehyde produced is much greater than for fully reduced or fully oxidized particles. Figure 11 shows the TDS traces equivalent to the ones shown for the single crystal in the relevant temperature range. It is clear that the deposited particles behave qualitatively similar, and it is tempting to assume the same mechanistic steps as more clearly underpinned by the single crystal data.

\section{Conclusions}

We have shown how vanadium oxide surfaces of different composition may be transformed into each other. The final reduction stage of $\mathrm{V}_{2} \mathrm{O}_{5}$ is $\mathrm{V}_{2} \mathrm{O}_{3}$ and it is possible to collect solid experimental information on reaction steps and mechanism. The results revealed for the single crystal surfaces may be transferred to the situation of vanadium oxide particles on a supporting oxide, i.e. silica.

The oxidation of methanol to formaldehyde was investigated for $\mathrm{V}_{2} \mathrm{O}_{3}(0001)$ thin films and deposited vanadia clusters. It is shown that the vanadyl oxygen atoms are involved in the reaction and that they influence its

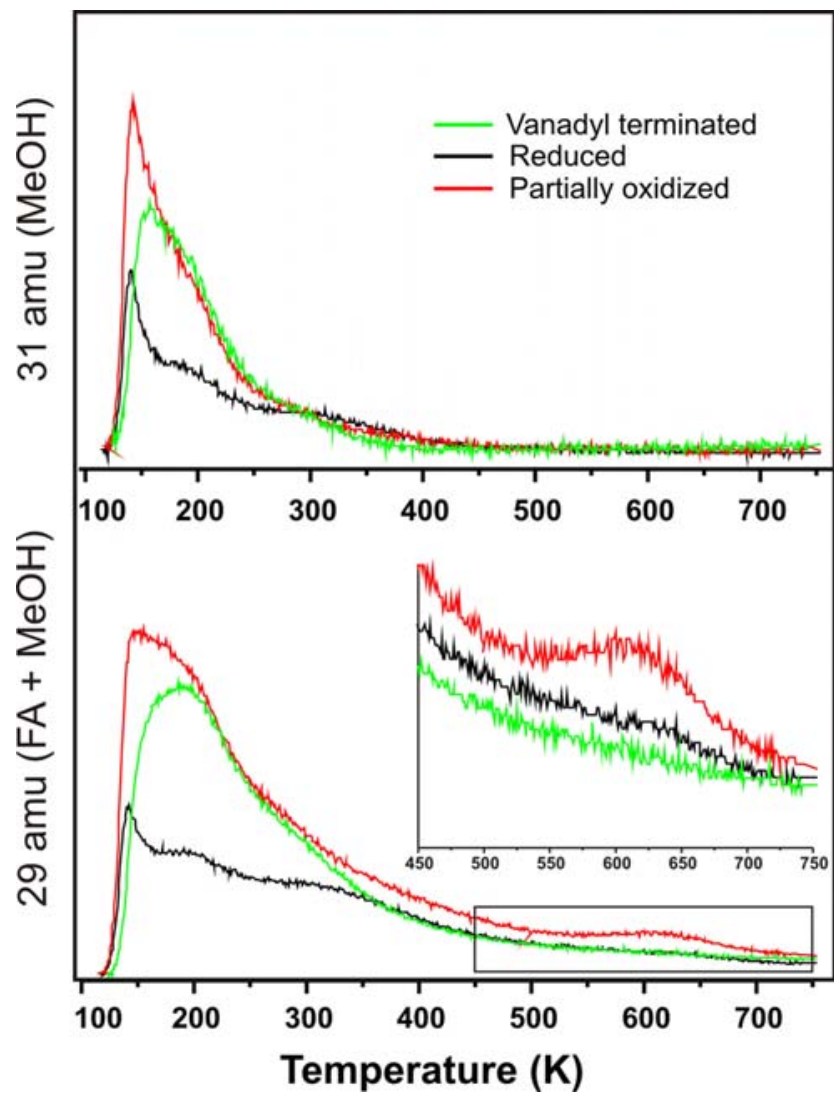

Fig. 11 TDS of methanol on vanadia particles (different degrees of reduction). About $1 \mathrm{~L}$ of methanol was adsorbed at $\sim 140 \mathrm{~K}$ in each case

selectivity. Indications were found that the band gap plays a prominent role for the reactivity.

This study indicates that through a combination of experimental work on well defined model systems in combination with theoretical modeling useful insight into catalytic active systems may be gained that are otherwise difficult or impossible to obtain.

Acknowledgments This work was supported by the Deutsche Forschungsgemeinschaft (Sonderforschungsbereich 546) and the "Fonds der chemischen Industrie". The calculations were carried out on the IBM pSeries 690 system of the Norddeutscher Verbund für Hoch- und Höchstleistungsrechnen (HLRN).

Open Access This article is distributed under the terms of the Creative Commons Attribution Noncommercial License which permits any noncommercial use, distribution, and reproduction in any medium, provided the original author(s) and source are credited.

\section{References}

1. Bond GC, Tahir SF (1991) Appl Catal 71:1

2. Deo G, Wachs IE, Haber J (1994) Crit Rev Surf Chem 4:141

3. Wachs IE (2005) Catal Today 100:79-94 
4. Argyle MD, Chen K, Resini C, Krebs C, Bell AT, Iglesia E (2004) J Phys Chem B 108:2345-2353

5. Argyle MD, Chen K, Iglesia E, Bell AT (2005) J Phys Chem. B 109:2414-2420

6. Chen K, Bell AT, Iglesia E (2002) J Catal 209:35-42

7. Döbler J, Pritzsche M, Sauer J (2005) J Am Chem Soc 127:10861-10868

8. Magg N, Giorgi JB, Schroeder T, Bäumer M, Freund HJ (2002) J Phys Chem B 106:8756-8761

9. Magg N, Giorgi JB, Hammoudeh A, Schroeder T, Bäumer M, Freund HJ (2003) J Phys Chem. B 107:9003-9010

10. Magg N, Giorgi J, Frank M, Immaraporn B, Schroeder T, Bäumer M, Freund H-J (2004) J Amer Chem Soc 126:3613

11. Magg N, Immaraporn B, Giorgi J, Schroeder T, Bäumer M, Döbler J, Wu Z, Kondratenko E, Cherian M, Baerns M, Stair PC, Sauer J, Freund H-J (2004) J Catal 226:88-100

12. Kaya S, Sun YN, Weissenrieder J, Stacchiola D, Shaikhutdinov S, Freund HJ (2007) J Phys Chem. C 111:5337-5344

13. Lu JL, Gao HJ, Shaikhutdinov S, Freund HJ (2006) Surf Sci 600:5004-5010

14. Dupuis A-C, Abu Haija M, Richter B, Kuhlenbeck H, Freund H-J (2003) Surf Sci 539:99-112

15. Abu Haija M, Guimond S, Romanyshyn Y, Uhl A, Kuhlenbeck H, Todorova TK, Ganduglia-Pirovano MV, Döbler J, Sauer J, Freund HJ (2006) Surf Sci 600:1497-1503

16. Guimond S, Abu Haija M, Kaya S, Lu J, Weissenrieder J, Shaikhutdinov S, Kuhlenbeck H, Freund H-J, Döbler J, Sauer J (2006) Top Catal 38:117-125
17. Gerberich HR, Seaman GC (1994) Kirk-Othmer encyclopedia of technical technology, vol 11. Wiley, New York, pp 929-951

18. Tatibouet JM (1997) Appl Catal A 148:213-252

19. Dupuis A-C, Abu Haija M, Richter B, Kuhlenbeck H, Freund HJ (2003) Surf Sci 539:99-112

20. Todorova TK, Ganduglia-Pirovano MV, Sauer J (2005) J Phys Chem. B 109:23523-23531

21. Blum RP, Niehus H, Hucho C, Ganduglia-Pirovano MV, Fortrie R, Sauer J, Shaikhutdinov S, Freund H-J (2007) Phys Rev Lett 99:226103

22. Perdew JP, Chevary JA, Vosko SH, Jackson KA, Pederson MR, Singh DJ, Fiolhais C (1992) Phys Rev B 46:6671

23. Perdew JP, Burke K, Ernzerhof M (1996) Phys Rev Lett 77:3865

24. Blöchl PE (1994) Phys Rev B 50:17953

25. Dudarev SL, Botton GA, Savrasov SY, Humphreys CJ, Sutton AP (1998) Phys Rev B 57:1505

26. Metropolis N, Rosenbluth AW, Rosenbluth MN, Teller AH, Teller E (1953) J Chem Phys 21:1087-1092

27. Ganduglia-Pirovano MV, Sauer J (2004) Phys Rev B 70:045422

28. Dillmann B, Rohr F, Seiferth O, Klivenyi G, Bender M, Homann K, Yakovkin IN, Ehrlich D, Bäumer M, Kuhlenbeck H, Freund H-J (1996) Farad Disc 105:295-315

29. Romanyshyn $\mathrm{Y}, \mathrm{PhD}$ Thesis HU Berlin (to be published)

30. Simic-Milosevic V, Nilius N, Rust HP, Freund H-J (2008) Phys Rev B 77:125112-1-125112-5

31. Kaya S, Weissenrieder J, Stacchiola D, Shaikhutdinov S, Freund HJ, Phys J (2007) Chem C 111:759-764 